American Journal of Economics and Business Administration 3 (3): 456-459, 2011

ISSN 1945-5488

(C) 2011 Science Publications

\title{
Business-to-Business: The Salesperson's Dilemma
}

\author{
${ }^{1}$ Gopala Ganesh and ${ }^{2}$ Somjit Barat \\ ${ }^{1}$ Department of Marketing and Logistics, University of North Texas, \\ 167 Union Circle, Denton, TX 76201, USA \\ ${ }^{2}$ Department of Marketing, Pennsylvania State University, \\ 1 Campus Drive, Mont Alto PA 17237, USA
}

\begin{abstract}
Problem statement: There is a lack of research on B2B e-commerce, especially involving input from B2B executives. To bridge that gap, we investigate whether (1) buyers and sellers differ significantly in their preference for traditional over the online purchase method across different products and across different purchase criteria and whether (2) buyers prefer the traditional over the online method across the straight rebuy, modified rebuy and new task buying situations. In the process, we test the following hypotheses: In general, buyers prefer traditional B2B over online for B2B purchases; buyers prefer the online over traditional method of transaction for straight rebuy; buyers prefer the traditional over online method of transaction for modified rebuy and buyers prefer the traditional over online method of transaction for new task. Approach: The authors queried B2B salespersons and B2B purchase professionals across a wide range of industries, representing a crosssection of products and purchase criteria. We use independent samples t-test for our hypotheses, since the main objective is to test direction and/significance of (differences in) preference. Results: The results show that traditional B2B is the buyers' preferred procurement method. Buyers, however, prefer the online method for straight rebuy transactions and the traditional method for modified rebuy and new task situations. Conclusion: Efforts to measure purchase preference from a B2B buyer's and seller's perspectives are few and far between, the main reason being the difficulty of collecting data from industry professionals. Given the popularity of B2B e-commerce and the interesting managerial and academic implications we have provided, the authors believe that this research provides valuable contribution. We also offer suggestions for future research.
\end{abstract}

Key words: Business-to-business, electronic commerce, purchase professionals, sales persons, academic implications, rebuy transactions, B2B e-commerce, B2B buyers, collecting data, empirical studies, census bureau statistics, hypotheses development

\section{INTRODUCTION}

Electronic commerce (e-commerce), i.e., commercial transactions mediated by the Internet, supported by software and services, creates mutual value for business partners through the performance of essential business functions better, faster, easier and cheaper (Polhamus, 2001). Business-to-Business (B2B) e-commerce deals with exchanges between two or more business entities.

The importance of the current topic is vindicated by industry reports, which show that e-commerce has experienced phenomenal growth over the last several years. For example, US e-commerce spending increased to $\$ 32.1$ billion in Q3 2010, which is a 9\% increase over Q3 2009. According to U.S. Census Bureau statistics, total retail spending for the first five months of 2010 was $\$ 1.25$ trillion, as reported by Comscore.com in their 2010 study US Census Bureau. In the same report, Comscore notes that consumer electronics, computer software, computers /peripherals/PDAs and books/magazines are some of the most hot e-commerce products Comscore Report.

Despite such notable figures and prospects, most previous studies have been reported by professional consultants who typically base their reports more on industry estimates and historical data rather than on empirical studies. Our research, in contrast, uses input from $\mathrm{B} 2 \mathrm{~B}$ professionals in a cross-section of industries, including raw materials, capital equipment and services. Such studies are very limited in past research, even though preliminary attempts were made by Webster (1965).

Corresponding Author: Gopala Ganesh, Department of Marketing and Logistics, University of North Texas, 1167 Union Circle, Denton, TX 76201, USA Tel: (940) 5653129 Fax: (940) 5653837 
Am. J. of Economics and Business Administration 3 (3): 456-459 2011

Table 1: Summary perceptions of sourcing supply

\begin{tabular}{|c|c|c|c|}
\hline & \multicolumn{3}{|l|}{ Mean for } \\
\hline & Significance $^{1}$ & $\begin{array}{l}\text { Buyers } \\
\mathrm{n}=166\end{array}$ & $\begin{array}{l}\text { Sellers } \\
\mathrm{n}=81\end{array}$ \\
\hline \multicolumn{4}{|c|}{ Across products and services } \\
\hline Traditional B2B is Better & 0.006 & 12.77 & 15.99 \\
\hline No Difference & 0.005 & 5.61 & 8.33 \\
\hline Online B2B is Better & n.s. & 5.10 & 5.70 \\
\hline \multicolumn{4}{|l|}{ Across buying situations } \\
\hline Traditional B2B is Better & n.s. & 1.48 & 1.68 \\
\hline No Difference & n.s. & 0.48 & 0.52 \\
\hline Online B2B is Better & n.s. & 0.82 & 0.75 \\
\hline \multicolumn{4}{|l|}{ Across purchase criteria } \\
\hline Traditional B2B is Better & n.s. & 7.75 & 8.35 \\
\hline No Difference & n.s. & 6.64 & 5.80 \\
\hline Online B2B is Better & 0.035 & 4.14 & 5.44 \\
\hline
\end{tabular}

Later academics who contributed to this line of research include Doyle et al. (1979); Johnston and Bonoma (1981) and Wilson (1995). We hoped that this approach would potentially yield interesting results with regard to buyers' and sellers' different (sometimes conflicting) interests in pursuing B2B e-commerce and would encourage further discussion among academics as well as practitioners.

The rest of the discussion is organized as follows: the next discussion provides a literature review, while comparing and contrasting the views of the B2B buyer and the salesperson. That is followed by a description of the data collection method and analysis. We then present the results of the analyses, which culminate in a discussion of their managerial and academic implications. The concluding section of this study points out its limitations and provides suggestions for further research.

Literature review and hypotheses development: A review of pertinent literature reveals that there exist six broad categories of products purchased by businesses, viz., (1) Raw/semi-manufactured materials; (2) Capital equipment; (3) Components/parts; (4) Installation equipment; (5) Supplies and (6) Services. Collectively, the experiences of dealing with these six product and service categories could lead to an overall perception of B2B e-commerce, influence the levels of perceived risk and uncertainty and the need for information in a B2B e-commerce environment (Kotler and Armstrong, 2011).

It must be emphasized that a buyer-seller dyadic relationship must be analyzed not only from an individual perspective, but also from an organizational perspective, becauseB2B exchanges are influenced as much by organizational characteristics as they are by the salesperson's negotiating capabilities. Therefore, the authors deliberately chose to use data from a crosssection of industry professionals who are responsible for making sales-related decisions on behalf of their organizations, rather than the head of a strategic business unit within each organization.

The involvement of the sales and purchasing teams are likely to be very high for purchases where negotiations about price, quality or other aspects of the transaction are involved. Such transactions often take anywhere between a week to more than two years to complete, depending on the complexity and/or the dollar value involved (Johnston and Bonoma, 1981). This motivates our first hypothesis:

H1: In general, buyers prefer traditional B2B over online for B2B purchases.

Straight rebuy' products are more likely to be conducive to Internet method of transaction than its traditional counterpart. In contrast, modified rebuy and new task might involve complexities in price, quality or quantity issues that are likely to require more face-toface interaction and arguably, the traditional model of transaction is more appropriate (Lamb et al., 2002). Therefore, we frame our second set of hypotheses:

$\mathrm{H} 2 \mathrm{a}$ : Buyers prefer the online over traditional method of transaction for straight rebuy

$\mathrm{H} 2 \mathrm{~b}$ : Buyers prefer the traditional over online method of transaction for modified rebuy

H2c: Buyers prefer the traditional over online method of transaction for new task

\section{MATERIALS AND METHODS}

The sample was assembled using a combination of identical mail and Internet versions. We ended up with responses from 166 B2B buyers and 81 B2B salespeople. All items in the survey instrument were based on reviews of industrial marketing textbooks (Pani and Agrahari, 2007; Lamb et al., 2002) and relevant refereed journal articles (Barat et al., 2006).

We asked the respondents to indicate which method-traditional or online buying-was better across 32 individual products on a five-point scale: 1 (traditional B2B much better) through 5 (online much better). Next, using the same 5-point scale, we queried the $\mathrm{B} 2 \mathrm{~B}$ professionals to indicate which method was better for three purchase situations: straight rebuy, modified rebuy and new task and then for five procurement categories (Table 1).

\section{RESULTS}

At first we measured whether B2B buyers prefer traditional or online method for buying the 32 specific products and services organized under six umbrella categories. The percentage distribution of results shows that only for the umbrella category of 'supplies', in general, do buyers perceive the online procurement method to be better. 
Am. J. of Economics and Business Administration 3 (3): 456-459 2011

Table 2: Preferred procurement mode across B2B buying situations

\begin{tabular}{|c|c|c|c|c|c|c|c|c|c|c|c|}
\hline & \multicolumn{5}{|c|}{ Buyers $n=153-154$} & \multicolumn{5}{|c|}{ Sellers $n=79-80$} & \multirow[b]{2}{*}{$\begin{array}{l}\text { B Vs S } \\
\text { Sig }\end{array}$} \\
\hline & $\begin{array}{l}\text { Traditional } \\
\text { B2B }(\%)\end{array}$ & $\begin{array}{l}\text { No } \\
\text { Diff }(\%)\end{array}$ & $\begin{array}{l}\text { Online } \\
\text { B2B }(\%)\end{array}$ & $\begin{array}{l}\text { Mean } \\
1-5\end{array}$ & Sig & $\begin{array}{l}\text { Traditional } \\
\text { B2B }\end{array}$ & $\begin{array}{l}\text { No } \\
\text { Diff }\end{array}$ & $\begin{array}{l}\text { Online } \\
\text { B2B }\end{array}$ & $\begin{array}{l}\text { Mean } \\
1-5\end{array}$ & Sig & \\
\hline Straight rebuy & 23 & 20 & 57 & 3.68 & 0.05 & 31 & 24 & 45 & 3.28 & $\mathrm{~ns}$ & 0.083 \\
\hline Modified rebuy & 58 & 19 & 23 & 2.29 & 0.05 & 63 & 19 & 19 & 2.13 & 0.05 & ns \\
\hline New task & 78 & 13 & 9 & 1.62 & 0.05 & 77 & 10 & 13 & 1.71 & 0.05 & ns \\
\hline
\end{tabular}

Note 1: The Likert-type scale ranged from 1=Traditional B2B to 5=Online B2B is much better. The \%s were calculated after collapsing the two extreme categories at either end. Note 2: The mean was calculated by assuming the 1-5 scale as an interval scale. The significance for each group is based on a one sample $t$ test with 3 as the test value. Note 3: Buyers versus Sellers were compared using the Independent Samples t-test

Buyers perceive traditional method to be better than online B2B for the remaining five umbrella categories as well as for overall, across all products and services combined-for which, the perceptions of the two groups is not significantly different. Moreover, buyers perceive traditional B2B to be better than online B2B for four of the five procurement umbrella criteria and on an overall basis, across all umbrella criteria and the individual ones (Table 2). Therefore, we find strong support for H1.

Results of the analysis of the three buying situations suggest that $\mathrm{B} 2 \mathrm{~B}$ buyers perceive online to be better for straight rebuy, while favoring traditional method for modified rebuy and new task--for both of which, the magnitude of preference is even stronger than that for straight rebuy scenario. These findings provide strong support for $\mathrm{H} 2 \mathrm{a}, \mathrm{H} 2 \mathrm{~b}$ and $\mathrm{H} 2 \mathrm{c}$. The pattern is quite similar for salespeople, resulting in no significant differences between the two groups across the three buying situations.

\section{DISCUSSION}

The results suggest that for purchases in general, buyers perceive traditional $\mathrm{B} 2 \mathrm{~B}$ to be better than online B2B. That both buyers and sellers perceive the traditional method as better than online method of transaction for all five umbrella categories and for 28 of the 32 products/services within these in our study, is convincing evidence of currently higher preference for traditional $\mathrm{B} 2 \mathrm{~B}$ over online procurement of B2B products.

As the findings suggest, buyers perceive online B2B to be better than traditional B2B when it comes to order tracking, delivery in general, finding what is available, vendor choice and speed of deal consummation. Perhaps buyers are responding to this issue from their own specific contexts, whereas sellers are responding from their customers' perspective. This result deserves further investigation.

As expected, buyers and sellers perceive the online B2B method of transaction to be better for straight rebuy. Finally, when we compared the buyers and sellers on the number of instances when the traditional buying or online buying was perceived to be better and when the two methods were perceived as no different, the results further reinforce our hypotheses $\mathrm{H} 1, \mathrm{H} 2 \mathrm{a}, \mathrm{H} 2 \mathrm{~b}$ and $\mathrm{H} 2 \mathrm{c}$. Overall, therefore, we found moderate to strong support for all our hypotheses, which provides credence to the theoretical framework of the current research.

Academic and managerial implications: In this research, we investigated issues likely to be considered by buyers and sellers when conducting B2B commerce via traditional method or online. Our results generally favor the traditional B2B method. A thorough understanding of the buyer's perception is important from business and managerial standpoints because it can result in substantial savings in cost, time and human resources. As an afterthought, such understanding by top level executives may help avoid long-standing antagonistic relations between the B2B buyer and seller (Wang and Benaroch, 2004). Our study is one of the few that have looked at these issues from the buyer's perspective (usual) and the seller's perspective (unusual). For these reasons, therefore, the authors believe that this research makes a valuable contribution.

\section{CONCLUSION}

The first limitation of this study is the small sample size (166 buyers and 81sellers). However, even smaller samples are not uncommon in this field of research, given the difficulty of collecting data from B2B professionals (Matthyssens and Faes, 1985; Doyle et al., 1979; Leigh and Rethans, 1984). Secondly, the salespersons were asked to respond to the questions from their buyer's perspective, which might have been difficult to do. However, salespersons who interact routinely with their buyers are expected to have a good idea of how the latter might respond. This has been cited as acceptable in industrial behavior research (Anderson et al., 1987). Moreover, we designed our instrument based on extant literature and provided adequate explanation of the situation. One can also extend the current study by using advanced statistical analysis (such as factor analysis, multivariate regression) to test whether the buyer's and seller's responses follow a similar or divergent pattern. 
Everybody agrees that B2B e-commerce is here to stay and will continue to flourish. What academics are unable to agree on is the degree of positive or negative impact it has on the performance of the organizations. This suggests that e-commerce is a double-edged sword and as such, this field is ripe with possibilities for additional research.

\section{ACKNOWLEDGMENT}

The researchers would like to gratefully acknowledge the financial support of the Institute of Supply Management, the Smeal School of Business at the Pennsylvania State University and two academic research grants from the University of North Texas in completing this research project).

\section{REFERENCES}

Anderson, E., C. Wujin and B. Weitz, 1987. Industrial purchasing: An empirical exploration of the buyclass framework. J. Mark., 71-86. DOI: $10.2307 / 1251648$

Barat, S., D. Lee, G. Ganesh and A.K. Paswan, 2006. B2B Ecommerce: Exploring US, Indian and Korean purchasing professionals. ISBM Report 32005, The Pennsylvania State University.

Doyle, P., A.G. Woodside and P. Michell, 1979. Organizations buying in new task and rebuy situations. Indust. Mark. Manage., 8: 7-11. DOI: 10.1016/0019-8501(79)90012-9

Johnston, W.J. and T.V. Bonoma, 1981. The buying center patterns and interaction patterns. J. Mark., 45: 143-156. DOI: 10.2307/1251549
Kotler, P. and G. Armstrong, 2011. Principles of Marketing. 12th Edn., Pearson Prentice Hall, Delhi, ISBN: 8131715477.

Lamb, C.W., J.F. Hair, C. McDaniel and C.D. McDaniel, 2002. Marketing. 6th Edn., SouthWestern, Cincinnati, Ohio, ISBN: 0324068611, pp: 751.

Leigh, T.W. and A.J. Rethans, 1984. A Script-theoretic analysis of industrial purchasing behavior. J. Mark., 48: 22-32. DOI: 10.2307/1251507

Matthyssens, P. and W. Faes, 1985. OEM Buying process for new components: purchasing and marketing implications. Indust. Mark. Manage., 14: 145-157. DOI: 10.1016/0019-8501(85)90033-1

Pani, A.K. and A. Agrahari, 2007. E-Procurement in Emerging Economies: Theory and Cases. 1st Edn., Thomson Gale, Farmington Hills, Mich., ISBN: 1599041537, pp: 342.

Polhamus, M., 2001. Choosing a software/service supplier for your client. Consult. Manage., 12: 51-55.

Wang, C.X. and M. Benaroch, 2004. Supply chain coordination in buyer centric B2B electronic markets. Int. J. Product. Econ., 92: 113-124. DOI: 10.1016/j.ijpe.2003.09.016

Webster, F.E. Jr, 1965. Modeling the industrial buying process. J. Mark. Res., 2: 370-376.

Wilson, D.T., 1995. An integrated model of buyerseller relationships. J. Acad. Mark. Sci., 23: 335345. DOI: $10.1177 / 009207039502300414$ 